\title{
O OLHAR DA PSICOLOGIA NO ABRIGO: UMA CARTOGRAFIA
}

\author{
Cecília de Castro e Marques \\ Rejane Czermak \\ Universidade do Vale do Rio dos Sinos, São Leopoldo, Brasil
}

\begin{abstract}
RESUMO: O presente trabalho investiga os modos de subjetivação em um núcleo de abrigos residenciais de proteção à infância e adolescência do Estado do Rio Grande do Sul, buscando perceber as possibilidades de atuação da psicologia que propiciem a expansão da vida dos abrigados de modo singular e criativo. A cartografia foi utilizada como método de investigação, e assim traçou-se um mapa que contempla as instâncias individuais, coletivas e institucionais envolvidas na constituição desse território. Encontramos atravessamentos da lógica disciplinar que tende a produzir sujeitos massificados junto à exacerbação dos fenômenos contemporâneos de enfraquecimento de laços, enfraquecimento da função simbólica e enfraquecimento da reflexão tanto individual quanto coletiva, acompanhados de manifestações de violência. Perante essa realidade, as práticas de grupo mostraram-se uma estratégia potente por possibilitarem aos sujeitos a expressão coletiva de suas questões como uma alternativa a soluções individualizantes.
\end{abstract}

PALAVRAS-CHAVE: crianças; adolescentes; abrigo; grupos.

\section{THE EYE OF PSYCHOLOGY ON SHELTERS: ACARTOGRAPHY}

ABSTRACT: The present study verifies the forms of subjectivity in a nucleus of residential shelters for protection of childhood and adolescence in the State of Rio Grande do Sul, Brazil. We aimed at grasping possible performances of psychology in the expansion of the lives of the sheltered youth in a singular and creative way. Cartography was used as an investigative method, and we drew a map considering the individual, the collective, and the institutional instances comprising this realm. We observed influences of the disciplinary logic that tends to produce stereotyped individuals, along with the exacerbation of contemporary phenomena such as the weakening of bonds, the weakening of symbolic functions, the weakening of both collective and individual reflection, followed by acts of violence. Facing this reality, the group exercises proved to be a strong strategy as they enabled the individuals to express their questions collectively as an alternative to individualistic solutions.

KEY WORDS: children; adolescents; shelter; groups.

Neste estudo buscamos conhecer os modos de subjetivação em um núcleo de abrigos residenciais (NAR) destinado a crianças e adolescentes protegidos pelo Estado do Rio Grande do Sul.

A produção subjetiva foi considerada da perspectiva da multiplicidade, entendendo-se que sua produção não é prioritariamente nem individual, nem coletiva ou institucional (Guattari, 1992), mas que a subjetividade se desenvolve para além do indivíduo, fazendo-se coletiva e coextensiva à produção do campo social num dado contexto histórico.

Assim, para falar dos NARs enquanto um contexto de vida específico, em um primeiro momento enfocamos o que se produziu em termos da institucionalização dos coletivos, desde a modernidade e na passagem para a pós-modernidade, contemplando sempre os processos de subjetivação presentes nessa passagem, de modo a obtermos uma compreensão das diversas maneiras pelas quais os indivíduos ou as coletividades se compõem nesses espaços.

Utilizamos a cartografia como método de investigação, traçando um mapa do local, onde são apontados os entraves e as possibilidades de mudança, bem como as estratégias que a psicologia pode adotar.

\section{Mudanças no modelo de abrigamento - da disciplina ao controle}

$\mathrm{O}$ abrigamento residencial de crianças e adolescentes, como hoje o conhecemos, veio substituir o abrigamento em grandes institutos que, em função de uma lógica muito específica de funcionamento, foram denominados por Goffman (1996) de Instituições Totais.

Na Instituição Total todos os aspectos da vida são realizados no mesmo local e sob uma única autoridade. 
Nesse tipo de instituição visualiza-se a exacerbação de uma lógica de disciplinarização, por um lado massificante, presente nas tarefas, horários e vestimentas iguais para todos, mas também simultaneamente individualizante, pois, mesmo que as tarefas cotidianas sejam executadas por um coletivo e para um coletivo, em um lugar comum, o desejo opera individualmente, cada um estando ligado à sua identidade, sem uma construção comunitária, sem desejo grupal.

Foi Foucault (Deleuze, 1992; Silva, R. N., 2004) quem situou essa lógica disciplinar, que emergia já nos séculos XVIII e XIX, com seu apogeu no século XX, como um modo de organização social em que se estabelecem e solidificam os meios fechados de confinamento que o autor vai situar em termos das instituições família, escola, exército, fábrica, hospital. Nessas instituições, a lógica disciplinar organiza os corpos no tempo e no espaço de modo a modelá-los conforme um ritmo e um lugar próprios para a solidificação do processo de produção industrial, que se instaurava naquele momento histórico.

No cenário contemporâneo, as Instituições Totais, como no caso dos abrigos, vêm tomando novas formas frente à emergência de uma nova lógica de organização social, que Silva, R. N. (2004) chama de segunda cena da subjetivação capitalística, na qual a disciplina entrou em crise. Deleuze (1992) situa esse período depois da Segunda Guerra Mundial. A sociedade disciplinar passa a ser substituída pela sociedade de controle. Nesta, a lógica que estava presente nos espaços fechados espalha-se a céu aberto, e o espaço social recortado pelos meios fechados de confinamento tende a tornar-se espaço liso, sem fronteiras claramente demarcadas pelas instituições; os moldes identitários fixos (pai de família, soldado, aluno, operário) forjados pela disciplina começam a ser substituídos por redes moduláveis, passíveis de mudanças constantes, resultando em indivíduos, coletivos e instituições com maior fluidez e mobilidade, porém com maior controle (Pelbart, 2000).

No que se refere ao controle, tem-se que essa subjetividade que facilmente se desterritorializa recebe do capital ofertas de territórios. O mercado produz fluxos a serem consumidos na formatação da subjetividade: são imagens, informação, conhecimento, sonhos, desejos, afetos. É possível consumir maneiras de ser. O capitalismo funciona disfuncionando as estruturas tradicionais, $\mathrm{e}$ é nesse sentido que a crise constante dos sujeitos e das instituições lhe é interessante, pois, disfuncionando, o capitalismo formata as subjetividades ao sabor do capital. Essa formatação opera o controle.

No cenário contemporâneo, vemos coexistirem modos disciplinares e a emergência avançada da sociedade de controle. As Instituições Totais vêm tomando novas formas; a partir da crise em seus interiores, emergiram mudanças que acompanham as novas tendências.
Conforme Dufour (2005), as instituições emergentes na atualidade são plásticas, a meio caminho entre alojamento de jovens e a cultura hospital-dia e asilo social, semelhantes a uma espécie de parque de diversão escolar. Entendemos que as Instituições Totais acompanham essa tendência, adequando-se aos modos da sociedade de controle. E incluo o abrigamento residencial de crianças e adolescentes entre essas Instituições Totais, num modelo que veio substituir o abrigamento em grandes institutos que funcionavam plenamente na lógica disciplinar como Instituição Total.

A proposta nos NARs (Núcleos de Abrigos Residenciais) é que cada casa tenha uma possibilidade autogestiva quanto às suas regras e rotinas, não sendo tudo comandado por uma direção distante e autoritária, mas sim por uma direção que dialoga e assim constrói os caminhos junto aos monitores.

Os abrigados não são loteados nas casas por tipologia (idade, sexo, diagnóstico), e assim existe, em cada uma delas, diversidade entre os mesmos. Suas atividades (escola, esportes, cursos, trabalho) são realizadas fora do abrigo, em diferentes turnos, não havendo uma rotina padronizada para todos. A própria arquitetura do local propicia circulação pela comunidade, pois as casas não possuem grades e inclusive durante o dia mantêm-se com portas e janelas abertas.

Nesse novo modelo, e em sua aparente fluidez, vemos claramente presentes algumas fortes linhas subjetivadoras contemporâneas, pois as crianças e adolescentes abrigados (além de serem o resultado do enfraquecimento dos laços familiares e comunitários e, como apontado por Dufour (2005), de seu conseqüente enfraquecimento da inscrição simbólica) se vêem excluídos do mercado de consumo por não desfrutarem de recursos financeiros, o que os coloca em uma posição duplamente desterritorializante - em relação à família e em relação à sociedade de consumo. A agressividade e a violência aparecem então como uma resposta possível a essa dupla exclusão, o que, por sua vez, acirra a lógica disciplinar ainda presente nos NARs como uma herança da antiga FEBEM (Fundação Estadual do Bem-Estar do Menor).

No regime disciplinar, o Estado e suas agências educacionais corretivas, sanitárias e militares tinham por função disciplinar, normatizar e individualizar suas crianças, jovens e adultos, e nesse modelo temos a FEBEM como uma dessas agências governamentais de controle social. A transição desse modelo de atenção a crianças e adolescentes no Brasil iniciou-se oficialmente somente em 1990, quando houve a regulamentação do artigo 227 da Constituição Federal, do qual se originou o Estatuto da Criança e do Adolescente (ECA). Aresponsabilidade pela proteção dos direitos da criança e do adolescente foi transferida do Estado para a sociedade civil através dos conselhos tutelares, subsistindo a parcela de poder e res- 
ponsabilidade do Poder Judiciário através da criação dos juizados da infância e da juventude e da subordinação a eles dos conselhos tutelares (Silva, R., 1998).

Os dispositivos do ECA não foram implantados imediatamente no Brasil e, considerando especificamente o Estado do Rio Grande do Sul, a FEBEM só foi extinta em 2002, concomitantemente à criação da Fundação de Assistência Sócio-Educativa (FASE) e da Fundação de Proteção Especial (FPE). Com essa subdivisão, institui-se a distinção entre o tratamento a ser dispensado a crianças e adolescentes vítimas de violência e abandono e o tratamento a ser dispensado aos adolescentes autores de ato infracional. Com isso foi alterada a lógica de atendimento direcionada a cada um desses públicos, especializando-se a FASE no atendimento exclusivo a adolescentes autores de atos infracionais com medida judicial de internação ou semiliberdade. Já a FPE, através dos NARs, ficou destinada à execução da medida de proteção - abrigo voltado a crianças e adolescentes vítimas de abandono, violência física e/ou psicológica e maus-tratos ou em situação de risco social ou pessoal devido à sua própria conduta (Fundação de Proteção Especial).

A partir do olhar do cartógrafo mergulhamos na compreensão das características do novo modo de organização das instituições de abrigo, cartógrafo este definido por Rolnik (1989) como um tipo de psicólogo que entende o desejo como produção de real social e embarca na constituição de territórios existenciais, acompanhando os movimentos do desejo em suas investigações. $\mathrm{O}$ que lhe interessa nas situações com as quais lida é saber o quanto a vida está encontrando canais de efetuação, avaliando o quanto as defesas que estão sendo usadas servem ou não para proteger a vida, para assim buscar sustentar a vida em seus movimentos de expansão.

\section{Os NARs - desejo em expansão}

Marin (1999), em suas observações quanto às mudanças em uma unidade em São Paulo de um modelo mais impessoal de Instituição Total para um modelo de atendimento diferenciado voltado para um menor número de crianças, percebeu que a garantia do espaço próprio (um lugar onde moro, a minha cama, a minha toalha, a assistente social que conhece a minha história) pode propiciar uma apropriação de um "si-mesmo", um movimento dinâmico e ativo dentro desse ambiente e a possibilidade de surgirem a demanda e o apelo; eis, para a autora, a origem do desejo.

A idéia de "si-mesmo" nos remete às formulações de Foucault, Deleuze e Guattari quanto à produção de subjetividade. Segundo Deleuze (1992), Foucault não emprega a palavra sujeito como pessoa ou forma de identidade, mas sim o termo subjetivação no sentido de processo e "si" no sentido de relação a si. Essa relação de força consigo é a forma como o sujeito entra em relação com a exterioridade e suas forças. Nesse encontro intensivo sujeito-mundo, a subjetividade é a própria experiência desse encontro, ou seja, uma dobra da força, como uma inflexão das forças do Fora. Dessa forma, o conhecimento de si é sempre simultaneamente conhecimento histórico, ético e político.

Ao viver, estamos sempre fazendo dobras. A constante criação de sentidos - simultaneamente de si e do mundo - passa por esses encontros intensivos que se engendram no cotidiano. Os sentidos que daí derivam podem ser tanto da ordem do inédito, do singular - quando são experimentados criativamente -, como da ordem da conservação, quando não conseguimos nos abrir para novas dobras e ocorrem as cristalizações que perpetuam modos de vida, operando repetições.

Assim, podemos compreender por que Marin liga a conquista da apropriação de "si-mesmo" à possibilidade do surgimento do desejo em abrigados. Em outras palavras, a autora enlaça a apropriação do desejo ao conhecimento de si e então entende que o modelo de atendimento mais personalizado torna-se um espaço de atendimento mais propício à criação de um ser desejante, e não apenas de um sujeito massificado no meio dos outros e passivo à rotina institucional.

Os institucionalistas já perceberam isso quando propõem que a autogestão, seu grande objetivo, é inseparável da auto-análise. O conhecimento da própria situação é o que possibilita uma autogestão que leve os coletivos a práticas que estejam menos à mercê das linhas molares, como, por exemplo, dos objetivos da grande linha molar capitalista que arrasta os modos de vida de acordo com os interesses do capital.

As linhas molares são duras por serem bem determinadas e visíveis (Deleuze, 1998); essas linhas concernem a todos os dispositivos de poder que trabalham nossos corpos, máquinas abstratas que nos sobrecodificam ao influenciar nossa maneira de perceber, agir, sentir. Mas os indivíduos ou grupos são feitos de linhas de naturezas diversas. Essas linhas se traçam, se compõem, imanentes umas às outras.

A esquizoanálise objetiva estudar as linhas e, para tanto, caracteriza mais dois tipos - a molecular, mais flexível, móvel, traça pequenas modificações. São linhas que fazem correr fluxos de desterritorialização, os quais lentamente desmancham territórios. Por último, a linha de fuga ou ruptura é a que nos leva ao desconhecido. Ela não é previsível, nem pré-existente e, quando traçada, traz consigo criação, conjugando todos os movimentos de desterritorialização. Acompanhar os movimentos dessas linhas é mapear o movimento do próprio desejo.

Marin indica que, quando se deixa de lado o aspecto puramente protetor, assistencialista, e, ao contrário, assume-se um papel discriminador, permite-se que apareçam as manifestações das diferenças, dos sujeitos e 
das reivindicações; então, buscamos saber se a instituição assumirá esse papel tão promissor, já que: "Quando a criança deixa de ser a 'coitadinha' e mostra-se potente, exige uma renovação: Qual passa a ser o papel do adulto? ... O que é diferença passa a ser um obstáculo, mais do que uma possibilidade de trabalho" (1999, p. 90). É no embate entre as linhas molares de conservação, tanto disciplinares como de controle, e as linhas moleculares e de fuga do desejo que, no contato com o cotidiano da instituição, observam-se as dificuldades dos monitores em trabalhar com as diferenças entre as crianças e com as manifestações desejantes das mesmas. Os monitores ainda trabalham atravessados pela lógica disciplinar (na FEBEM, a primeira definição documentada de sua função era a manutenção da disciplina), como quando dificultam a circulação dos abrigados pela comunidade, proibindo-lhes a saída em várias situações, e quando exigem um comportamento perfeito da clientela e se utilizam de castigos pesados para puni-la.

Outro resquício das Instituiçõos Totais, presente ainda hoje, é o recebimento de tudo pronto e padronizado, como a comida, as roupas, os materiais escolares. Os abrigados não passam pela experiência de escolher a comida; na hora do almoço, são obrigados a comer até o que não gostam, devido às recomendações da equipe de nutrição; não escolhem roupas, não escolhem praticamente nenhum dos objetos que irão acompanhá-los no dia a dia. Em algumas casas, nem sequer se servem da comida nos próprios pratos. São situações como essas que massificam e prejudicam a emergência de singularidades.

Além disso, essas crianças encontram uma instituição que não profissionaliza seus funcionários, em especial o monitor, um trabalhador que está em contato cotidianamente com as crianças, em uma proximidade uns com os outros que propicia intensa afetação entre eles. Esses monitores acabam usando como modelo de trabalho o pai e a mãe que são em sua vida particular, com padrões de moral e concepções de educação diferentes entre si.

Os profissionais de saúde da instituição, incluindo os psicólogos, estão voltados prioritariamente para o atendimento da clientela em um modelo clínico tradicional. Os encaminhamentos de crianças e adolescentes para o serviço de psicologia são feitos, em geral, devido a maus comportamentos nas casas (agressividade, recusa em fazer tarefas ou fugas constantes); dificuldades escolares; anormalidades no sono; ansiedade e agitação motora, entre outros. Outra forma comum de procura pelos serviços da psicologia no local ocorre quando os adolescentes trazem queixas quanto a dificuldades de relacionamento com os monitores.

Entendendo como um risco ligar-se às queixas e compreendê-las como sentimentos particulares isolados do contexto, a escuta clínica realizada nesse contexto específico extrapola a pequena sala de atendimento e, conseqüentemente, as tarefas previstas são ampliadas. Para além dos monitores e de suas reclamações e para além do sofrimento psíquico individual de cada paciente, o olhar amplia-se necessariamente para manifestações que atravessam todo o NAR, desde as crianças até a direção.

Debruçamo-nos com maior profundidade sobre duas dessas manifestações que atravessam todo o NAR e que foram tratadas como analisadores, no sentido institucionalista do termo, onde os analisadores presentes em um certo campo de estudo são situações, fenômenos, práticas que manifestam e denunciam o funcionamento institucional, além de serem elementos que contribuem para o processo de análise: "analisador colocado em condições propícias, tem a possibilidade de não apenas manifestar-se, mas também de compreender; ele não precisa ser analisado de fora, ele precisa que se lhe aportem condições para auto-analisar-se, sendo assumido por seus protagonistas" (Baremblitt, 1998, p. 71).

Examinaremos primeiramente a dificuldade de escuta. Nosso primeiro encontro com esse fenômeno foi no grupo semanal das psicólogas com os adolescentes. Esse grupo teve sua proposta construída a partir de entrevistas individuais com os adolescentes de um NAR. Buscou-se torná-lo um espaço dentro do NAR para o fortalecimento da convivência em grupo, um potencializador de trocas que colaborassem para o desenvolvimento de um projeto de vida singular, com propriedade para solucionar seus próprios problemas através de um espírito coletivo.

A construção do grupo foi inspirada nas idéias de grupo dispositivo (Barros, 1997) e de texto grupal (Fernández, 2006).

Pensar o grupo como um dispositivo significa tentar fazer com que nele se acionem tensões, movimentos, deslocamentos para outro lugar, provocando novos agenciamentos e assim permitindo irrupção do que está bloqueado de criar. Coordenar um grupo dispositivo implica permitir que nele ocorra liberdade de movimento, de transformação, e abertura da dobra para os devires. Nada mais propiciador para essa abertura que o encontro entre pessoas, momento privilegiado de troca de afetos e intensidades onde, na afetação pelo outro, os indivíduos podem deslocar-se de lugares cristalizados, experimentando o novo em si e no outro. Experiência absolutamente criativa de invenção de si na vivência grupal.

O grupo é feito de conexões, de compartilhamentos imaginários, mitos, cristalizações e potencialidades quando se abrem nele caminhos para seus fluxos produtivos. A estes, Fernández vai chamar de texto grupal. O que se costuma chamar de contexto grupal, que seria a realidade externa que influencia os acontecimentos grupais, é pensado como texto grupal, no qual a realidade externa é vista como parte do grupo, e o texto refere sua produti- 
vidade. O texto grupal gera sentidos no deslizamento de movimentos corporais e espaciais, na pronúncia das palavras, nos silêncios e nas intensidades muitas vezes imperceptíveis aos olhos.

Ocorrem, nesse movimento grupal, enlaces e desenlaces de subjetividades, de modo que Fernández (2006) propõe o uso metafórico do nó para pensar os enodamentos e desenodamentos de subjetividades na cena grupal.

As autoras do presente artigo articulam esse conceito de nó com a idéia de linhas, pois na cena grupal temos as linhas de desejo imanentes formando diferentes nós. Acompanhar as múltiplas inscrições do nó grupal nos percursos do grupo é ler seu texto.

A participação no grupo não era obrigatória, nem a freqüência. Mesmo assim, o número de participantes era relativamente grande: entre oito e quinze participantes em cada encontro. Nos encontros semanais era difícil para a coordenadora conquistar a escuta, o que levava a uma demora de meia hora até que se iniciasse o diálogo. As atividades foram muitas, sempre construídas a partir dos pedidos deles: discussões sobre sexualidade, drogas; histórias de fantasmas; conversas sobre diferenças entre meninos e meninas, sobre dificuldades na relação com os monitores, também sobre as diferenças entre morar com a família e morar no abrigo; oficinas sobre entrevista de emprego e tipos de profissões; teatro com tema e roteiro feitos por eles; sarau poético, etc.

No desenrolar das atividades foi freqüente a irritação de uns com os outros, o motivo sendo muitas vezes o mesmo: porque, a princípio, eles não se escutavam. Conquistava-se a escuta com muito esforço, com muitos pedidos de silêncio, pedidos de atenção para quem estava falando, solicitações para que alguém mais agitado se retirasse um pouco até se acalmar e poder retornar. E, mesmo assim, às vezes, nada disso funcionava e eles brigavam; dentro do grupo brigavam gritando e, fora dele, no caminho de volta até as casas, as brigas eram corporais, já que uma das regras construídas por eles era que quem agredisse fisicamente no grupo ficaria fora do encontro seguinte e, para que isso não acontecesse, adiavam a briga para a hora da saída.

A dificuldade de escuta tem relação com a inscrição simbólica, com a dificuldade de relação com o discurso do outro, uma dificuldade contemporânea exacerbada no local. Com tempo, percebeu-se que essa não era uma particularidade do grupo de adolescentes, pois o diálogo entre monitores era também pouco fluente, bem como o diálogo entre direção e monitores. Havia pouco aproveitamento dos espaços de reflexão, como as reuniões periódicas e o grupo da psicologia para monitores, o qual contava com pequena participação dos mesmos. Havia ainda um fenômeno de muita fofoca e "telefonesem-fio" entre os trabalhadores no NAR, pois dificilmente as queixas em relação ao colega eram discutidas com este. Os queixosos falavam para a direção ou para outro colega, de modo que a informação voltava à sua fonte transformada, gerando mal-entendidos.

Nas reuniões de equipe observaram-se muitas semelhanças com o grupo dos adolescentes. As pessoas falavam alto, uma fala sobrepondo-se à outra, quando não atropelando uma a outra, situações que mostravam, concomitantemente à dificuldade de escuta, a escassez de reflexão compartilhada. Cada um buscava resolver seus problemas solitariamente, operando seu desejo individualmente, comportamento que deflagrava o atravessamento contemporâneo de supervalorização do indivíduo e desinvestimento dos coletivos e dos espaços públicos.

Mostramos a seguir a segunda das manifestações, a comunicação pelo ato, quando, esgotadas as possibilidades de solução dos conflitos através do diálogo, as pessoas se manifestam pela violência.

A violência mostrou-se presente em todas as instâncias institucionais. Soube-se dela no interior "protegido" das casas, onde existem proibições sem nenhuma lógica, onde ocorrem agressões verbais e físicas entre crianças e monitores. Perceberam-se, ainda, manifestações mais sutis de violência, como a que parte da direção quando, por exemplo, manda embora para outro abrigo o monitor que não trabalha de acordo com o esperado, bem como os esquecimentos de levar as crianças aos atendimentos psicológicos, mesmo quando estes ocorrem dentro do NAR.

O que vemos é, por um lado, a banalização da violência e, por outro, sua presença constante, persistente, com uma insistência em fazer-se vista, em fazer-se escutada, como tantas vezes aparecia no grupo. A solução encontrada pelos abrigados, seguidas vezes, é fugir para a rua ou para a família de origem, estratégia geralmente adotada por adolescentes, alguns inclusive que nunca mais voltam. As fugas são manifestações do desejo, que são por sua vez rompimentos com o modo de relação no interior das casas. Os monitores muitas vezes entendem essas fugas como dificuldade do adolescente e não analisam sua implicação com o resultado do desejo dos abrigados de irem embora da casa.

No espaço em que se encontram todos os monitores de cada casa, qual seja, a reunião mensal com a direção e a equipe técnica, a proposta é a discussão dos casos. Pouco se discute a própria equipe em sua relação com as crianças. Em nossas participações em reuniões buscavámos dialogar sobre casos em atendimento, e todo o trabalho objetivava direcionar a reflexão para o modo como o ambiente apresentava-se para a criança, para o modo como um grupo poderia unir-se para criar soluções conjuntas. Tais pontuações eram pouco compreendidas, porque a fala do grupo dirigia-se para queixas sobre os comportamentos da criança, e era muito difícil 
levantar uma reflexão direcionada à relação com a criança, direcionada a como o grupo poderia trabalhar de modo a potencializar a criança.

Percebeu-se, através dos analisadores, o quanto o coletivo NAR expressa uma crise que se manifesta nas relações humanas, condizente com o cenário contemporâneo de minimização da reflexão, tanto individual quanto compartilhada. Nesse sentido, a crise pode ser experimentada como linha de desterritorialização se a fizermos funcionar verdadeiramente como analisador, colaborando para que os coletivos façam reflexões quanto à própria crise, apropriando-se de seu poder transformador como uma linha de fuga.

Assim, diante dos tantos fatores que compõem esse território existencial, percebe-se a importância de tratar as demandas clínicas não exclusivamente como sintomas particulares das crianças e dos adolescentes que existem no cruzamento de linhas (disciplinares, identitárias, massificantes, desterritorializantes, entre outras). Assim sendo, devemos tratá-los como seres ativos que, com o trabalho clínico, tanto individual quanto ampliado para o grupo, podem se tornar artesãos de suas vidas, o que implicará também reinvenção do ambiente em que vivem. Então, quando o profissional da psicologia dialoga com os monitores, busca ajudá-los a acolher os movimentos de mudança na criança - tarefa que compreendemos não ser simples, já que provoca mudanças também no monitor.

Acompanhamos o entendimento de Paulon (2004) sobre a tarefa do psicólogo: para a autora, significa arriscar-se no ensaio de criar estratégias que acompanhem as modalidades variadas de constituição de subjetividade, desenvolvendo a clínica como tecnologia da subjetividade, o que a compromete com as formas de ser no mundo. Essa postura inclui a investigação de agenciamentos desejantes que apontem saídas singulares para a transformação e construção de dispositivos e estratégias que desnaturalizem o que é da ordem da história e coletivizem o que se transveste de sintoma individual.

Dessa forma, além do atendimento clínico individual, que não deixa de ser importante, pensa-se nos grupos como potente estratégia da psicologia na medida em que as manifestações foram percebidas primeiramente em grupo e que também foi nele que elas começaram a funcionar como analisadores. Os grupos se mostraram espaços de reflexão compartilhada e de construção coletiva. Com o desenrolar dos encontros, a violência que era ato passou, por exemplo, a ser dramatizada em uma peça teatral com texto criado coletivamente.

A história tinha início em um baile funk onde parte do grupo dançava, alguns fumavam maconha e um menino vendia a droga. A polícia fazia uma batida e levava os fumantes de maconha e o traficante para a delegacia. Como eles eram menores de idade, não foram presos, e a próxima cena é de uma audiência com uma juíza. Na montagem dessa cena, conversamos sobre para onde a juíza mandaria cada um e descobrimos que os adolescentes não conheciam a diferença entre FPE e FASE. Após esclarecimentos sobre a diferença, decidiram que nenhum iria para a FASE. Apresentaram então duas audiências: em uma delas, os pais acompanhavam o adolescente usuário de maconha e responsabilizavam-se por manter o filho em tratamento, por cuidar dele; na segunda audiência, os pais não se comprometem com nada, e o traficante ganha uma "chance" da juíza e vai para a FPE. A cena seguinte se dá nas casas-abrigo.

Nesse momento da peça, alguns faziam papel de monitor e outros de abrigados. Então eles recebiam um novo morador, e a cena desenrolava-se no sentido de incluir o cotidiano da casa. Nessa parte, o grupo tornouse totalmente autogestor e não houve mais intervenção das coordenadoras, que se tornaram espectadoras da cena. O mais notável é que parecia que a qualquer momento eles perderiam o controle, e o que era teatro viraria realidade, pois a cena era de uma violência intensa: abrigados que na casa brigavam uns com os outros, que roubavam coisas da casa e monitores que gritavam "Vou te levar para o DECA" (Departamento Estadual da Criança e do Adolescente). Os monitores desesperavam-se, xingavam os abrigados, perdiam o controle; os abrigados surtavam e eram contidos e levados para o plantão médico. Muito movimento numa cena que representava uma casa pulsante.

Esse momento de união e produção coletiva vivido pelo grupo deflagrou o cotidiano vivido por eles, mesmo que em diferentes casas, com diferentes monitores. Foi um momento de compartilhamento e de expressão da multiplicidade que envolve o modo de vida nas casas e, dessa vez, sem violência - pelo contrário, com arte. Vemos aí a criação de uma nova potência de si, que, conforme Czermak (2005), sempre passa por uma vivência de alteridade, sendo próprio dos fluxos desejantes ligarem-se a novos objetos, recriando os modos de existência.

A experiência no grupo com adolescentes inspirou a criação de grupos para crianças e de um grupo sobre entrada no mundo do trabalho para os que tinham acima de quinze anos. Mais adiante, esse trabalho inspirou mais conexões, como o encontro do grupo das crianças com o grupo de adolescentes para montagem de uma peça para o Dia das Mães, que foi apresentada para monitores, direção e equipe técnica.

Quando da impossibilidade de montar grupos, como ocorreu com os monitores, as conversas, mesmo nos encontros mais cotidianos (pelo telefone, na cruzada do corredor, no levar e buscar uma criança ao atendimento, no breve encontro na direção), passaram a ser valorizadas. Afinal, também eram encontros e, portanto, permeados por afetos. 
Num lugar onde as trocas reflexivas são tão raras, onde a comunicação insiste em irromper pelo ato, é preciso apostar em cada momento de escuta e de troca e reconhecer o seu valor, aproveitando cada oportunidade de comunicação.

Buscamos, ainda, manter o diálogo constante com a direção e a equipe técnica, acionando a potência do trabalho interdisciplinar. Quanto à rede externa, buscouse dialogar com as escolas e com os demais atendimentos à criança e ao adolescente e também com cursos profissionalizantes na comunidade.

Essas ações visaram, de um modo geral, a oferecer alternativas à comunicação e à afirmação do desejo através da violência. Afinal, acreditamos que, mesmo no cenário contemporâneo de enfraquecimento dos laços e das instituições, o abrigo pode ser um espaço de ancoragem psicossocial onde as crianças e os adolescentes poderiam desenvolver-se, protegidos após os sofrimentos vividos em suas casas de origem. Para tanto, os trabalhadores precisam estar envolvidos na construção constante de uma instituição que não fique apenas a meio caminho entre a escola, a rua e a família de origem, mas que se ofereça como lugar de acolhimento, como um lar que pode vir a ser inventado.

O processo de mudança implica um tecido de relações e pode muitas vezes ser lento, mas o importante não é tanto a velocidade, e sim o movimento. Pois, como Deleuze nos mostrou, se explodimos com as linhas duras, explodimos a nós mesmos, porque elas também nos compõem, e por isso é preciso soltá-las lentamente.

\section{Referências Bibliográficas}

Baremblitt, G. (1998). Compêndio de análise institucional e outras correntes: teoria e prática ( $4^{\mathrm{a}}$ ed.). Rio de Janeiro: Rosa dos tempos.

Barros, R. D. B. (1997). Dispositivos em ação: o grupo. In: Lancetti, A. (Org.), Saúde Loucura, n. 6. (pp. 183-191). São Paulo: Hucitec.

Czermak, R. (2005). Do significado ao ato: sentido e criação na análise. Estudos de Psicanálise, 28, 117-121.

Deleuze, G. (1992). Conversações: 1972-1990. Rio de Janeiro: Editora 34.

Deleuze, G. \& PARNET, C. (1998). Diálogos. São Paulo: Escuta.

Dufour, D. (2005). A arte de reduzir cabeças. Rio de Janeiro: Editora Companhia de Freud.

Fernández, A. M. (2006). O campo grupal: notas para uma genealogia. São Paulo: Martins Fontes.

Fundação de Proteção Especial. (s.d.). Acesso em 12 de novembro, 2006, em http://www.stcas.rs.gov.br/fpe_01/quem_somos.htm

Goffman, E. (1996). Manicômios, prisões e conventos (5 ${ }^{\mathrm{a}} \mathrm{ed}$.). São Paulo: Editora Perspectiva.

Guattari, F. (1992). Caosmose: um novo paradigma estético. São Paulo: Editora 34.

Marin, I. da S. K. (1999). Febem, família e identidade: (O lugar do Outro) ( $2^{\mathrm{a}}$ ed.). São Paulo: Escuta.
Paulon, S. M. (2004). Clínica Ampliada: que(m) demanda ampliações? In T. M. G. Fonseca \& S. Engelman (Orgs), Corpo, arte e clínica. (pp. 259-273). Porto Alegre: Editora da UFRGS.

Pelbart, P. P. (2000). A vertigem por um fio: políticas da subjetividade contemporânea. São Paulo: Iluminuras.

Rolnik, S. (1989). Cartografia sentimental: transformações contemporâneas do desejo. São Paulo: Estação Liberdade.

Silva, R. (1998). Os filhos do governo: a formação da identidade criminosa em crianças órfãs e abandonadas. São Paulo: Ática.

Silva, R. N. (2004). A dobra deleuziana como potência de invenção. In T. M. G. Fonseca \& S. Engelman (Orgs.), Corpo, arte e clínica. Porto Alegre: Editora da UFRGS.

Cecília de Castro e Marques possui graduação em Psicologia pela Universidade do Vale do Rio dos Sinos (2007). Tem experiência na área de Psicologia. E-mail: cecic@terra.com.br

Rejane Czermak é Psicanalista, Dra. em Psicologia Clínica pela Universidade Livre de Berlim, professora titular no Curso de Psicologia da Universidade do Vale do Rio dos Sinos. Endereço para correspondência: Curso de Psicologia/ Centro de Ciências da Saúde, UNISINOS. Av. Unisinos, 950. CEP: 93022000. São Leopoldo, RS. Email: czermak@unisinos.br

O olhar da psicologia no abrigo: uma cartografia

Cecília de Castro e Marques e Rejane Czermak

Recebido: 17/09/2007

$1^{\mathrm{a}}$. Revisão: $13 / 11 / 2007$

$2^{\text {a }}$. Revisão: 30/01/2008

Aceite final: 06/05/2008 